\title{
Reading computer-presented text
}

\author{
SUSAN M. BELMORE \\ University of Kentucky, Lexington, Kentucky
}

\begin{abstract}
This experiment compared self-paced reading time and comprehension for subjects who read both paper- and computer-displayed passages. Reading time was longer and comprehension was less accurate for computer presentation than for paper presentation, but only when subjects were tested on the computer-presented texts first. These data raise the possibility that the processes involved in reading video text may not be comparable to traditional reading, especially without extensive practice on a given task. It is suggested that data from computer-controlled reading experiments that use relatively brief testing sessions should be viewed with caution.
\end{abstract}

One consequence of the use of computers is that verbal material is read from a video screen instead of from books and paper. Textbooks, novels, and newspapers of the future are more likely to be read directly from home computer terminals than from the traditional printed page. In the psychological laboratory, computer-controlled systems are already routinely used to conduct experiments on human behavior, including studies of reading itself. This widespread use of computer-presented text in studies of reading is based on a largely untested assumption: that the mental processes involved in reading computerpresented text are roughly equivalent to those used in reading the printed page.

Most of the available research on computer-presented text has focused on peripheral aspects of processing, such as eye fatigue (Mourant, 1981) and presentation speed (Bevan, 1981). Few studies have explicitly compared the comprehension of semantic content from computerdisplayed and paper texts. One recent attempt is a study (Muter, Latremouille, Treurniet, \& Beam, 1982) in which students were tested on eight comprehension questions after reading for $2 \mathrm{~h}$ from either a computer screen or a book. The results showed slower reading time for the computer text, but no differences on the comprehension test. Unfortunately, the authors suggested that their comprehension test may have provided an inadequate assessment of differences between the two modes. Belmore (1983) also showed equivalent amounts of learning from traditional and computer-controlled versions of the same lab module, but did not provide a direct test of reading comprehension. Given the pervasiveness of computerpresented text in both applied and laboratory settings, there is a critical need for further information about possible processing differences between these modes of presentation.

The act of reading video text differs from that of reading a book in a number of physical characteristics, in-

The author is indebted to Meg Howard and Rich Birndorf for assistance in programming and conducting this research. Reprint requests may be addressed to the author at the Department of Psychology, 115 Kastle Hall, University of Kentucky, Lexington, KY 40506. cluding body posture, orientation of the head and eyes, and figure-ground contrast. Although any of these factors might affect reading time, none of them compels the prediction that the comprehension of meaning should be inherently more difficult in one mode than in the other. The relative unfamiliarity of computer text might be expected to produce a temporary impairment in comprehension for adults with a lifetime history of reading from paper, but such a decrement in performance should be short-lived. One characteristic of computer-presented text that might affect comprehension is that successive screens in a computer display cannot be "turned" in the same way as pages in a book. This suggests that any comparison of paper and computer presentation modes should use video text programmed in a format that allows subjects to refer to earlier parts of the text for clarification.

The experiment reported here compared reading time and comprehension for subjects who read four passages in each of the two presentation modes (traditional and computer-presented). Questions requiring semantic analysis were used to assess comprehension for each of the passages.

\section{METHOD}

\begin{abstract}
Materials
The stimulus materials were eight short passages, each accompanied by multiple-choice comprehension questions. The passages and questions were adapted from materials in standardized reading tests (Didas, 1962; Nelson \& Denny, 1960). The texts ranged from one to five (mean $=$ two) paragraphs and 127 to 221 (mean $=187$ ) words in length. The texts chosen represented a variety of topics and styles, including narrative, expository, and persuasive texts. Six of the eight passages had four multiple-choice questions; one of the remaining passages had three and one had five questions. Care was taken to ensure that the comprehension questions focused on general semantic content, such as the theme or setting of the passage, rather than on details. All comprehension tests were typed on paper, regardless of passage mode.

For the paper presentation mode, each passage was typed single-spaced in capitals and lowercase letters on a separate sheet of white bond paper. The typed versions of the passages contained a maximum of 25 lines and 47 characters per line.

In the computer presentation mode, the passages appeared in capitals and lowercase letters on the monitor of an Apple II Plus 48K microcomputer. The monitor displayed a maximum of 24 lines per screen and 40 characters per line; no passage required more than two successive
\end{abstract}


screens. The subjects were able to move one screen backward or forward by pressing one of two buttons on the computer keyboard. The time required to replace a complete screen of text was less than $1 \mathrm{sec}$.

\section{Procedure}

The subjects were 20 undergraduates who participated for extra credit in an introductory psychology course. The 1-h testing session was conducted in a departmental computer lab under quiet conditions.

Presentation mode was a within-subjects variable: Each subject read four of the passages printed on paper and the other four displayed on the computer screen. The eight passages occurred in a constant order for all subjects. Half of the subjects read the first four passages in the computer mode (the C-P condition), and the other half read the same passages printed on paper first (the $\mathrm{P}-\mathrm{C}$ condition). Thus, a given passage occurred in each presentation mode for equal numbers of subjects.

Instructions to the subjects urged them to read each passage through once at their normal speed, and to read for meaning in anticipation of a comprehension test. They were given practice in changing screens with the control keys before they began the computer-presented passages. The experimenter timed the interval from a "Ready" signal until the subject said "Finished" at the end of each passage. Immediately after the subject had finished reading each passage, the passage was removed and the subject was given the sheet containing comprehension questions for that passage.

\section{RESULTS}

\section{Reading Time}

Reading time was averaged across the four passages in each presentation mode for each subject. These data are shown in Table 1 . A $2 \times 2$ ANOVA (presentation mode $X$ order) showed no overall effect of presentation order (P-C vs. C-P). The subjects spent a significantly longer time (mean $=94 \mathrm{sec}$ ) reading the computer-presented texts than they did the paper-presented texts (mean = $84 \mathrm{sec})[\mathrm{F}(1,18)=26.73, \mathrm{MSe}=601.3, \mathrm{p}<.001]$. This effect was qualified by a mode $\times$ order interaction $[\mathrm{F}(1,18)=52.43, \mathrm{MSe}=37.79, \mathrm{p}<.001]$. Follow-up tests (Tukey's HSD) showed that presentation mode significantly affected performance on the first four passages $[\mathrm{t}(18)=4.87]$ but not on the last four passages.

\section{Comprehension}

The mean number of comprehension questions answered correctly for passages in each presentation mode is also shown in Table 1. A $2 \times 2$ ANOVA indicated that both main effects and the interaction were significant.

Table 1

Mean Reading Time (in Seconds) and Comprehension (Percent Correct) as a Function of Presentation Mode and Presentation Order

\begin{tabular}{lccc}
\hline & \multicolumn{2}{c}{ Presentation Mode } & \\
\cline { 2 - 3 } & Computer & Paper & Overall Mean \\
\hline & \multicolumn{2}{c}{ Reading Time } \\
C-P Order & 103 & 79 & 91 \\
P-C Order & 85 & 89 & 87 \\
Overall Mean & 94 & 84 & 89 \\
& \multicolumn{5}{c}{ Comprehension } & \\
C-P Order & 16 & 58 & 37 \\
P-C Order & 52 & 69 & 61 \\
Overall Mean & 34 & 64 & 49 \\
\hline
\end{tabular}

Overall, the subjects in the P-C condition showed better comprehension than the subjects in the C-P condition $[\mathrm{F}(1,18)=20.79, \mathrm{MSe}=2.69, \mathrm{p}<.001]$. Performance was dramatically better for paper (mean $=64 \%$ correct) than for computer texts $($ mean $=34 \%)[\mathrm{F}(1,18)=54.80$, $\mathrm{MSe}=1.64, \mathrm{p}<.001]$. The interaction term $[\mathrm{F}(1,18)$ $=9.62, \mathrm{MSe}=1.64, \mathrm{p}<.01]$ again showed that the difference due to presentation mode occurred for the first four passages $[\mathrm{t}(18)=9.37]$ but not for the second four passages.

To summarize the results: The subjects read significantly longer and comprehended less with computer-presented than with paper-presented text. However, there was no disadvantage for computer text in either reading time or comprehension when subjects were tested on the paperpresented passages before reading the computer-presented texts. Whether this finding represents passage effects or practice effects cannot be determined, since the texts always occurred in a constant order. An examination of performance at each serial position showed no evidence of improvement across the four passages in a given presentation mode, suggesting that any practice effects involved experience with the task itself rather than practice with computer-presented text.

\section{DISCUSSION}

These data indicate that reading texts on a computer display is not equivalent to reading the same texts on paper: Overall, college students took $12 \%$ longer to read and comprehended $47 \%$ less with computerpresented text than with paper-presented text. However, the observed disadvantage for computer texts in both speed and comprehension was greatly reduced or eliminated when the subjects were tested on the paperpresented passages first. This result was identified as a task-specific rather than a modality-specific practice effect.

The subjects in the computer-first condition showed an inverse relation between study time and performance on the computer texts, since they spent much longer studying the passages but retained less of the content on an immediate test of comprehension. The longer reading times in this condition presumably reflected the subjects' difficulty in understanding the computer-presented material rather than semantic elaboration of the content (see Baddeley, 1978, and Craik \& Lockhart, 1972).

The most likely explanation of the decrement in performance for this group is that the novel aspects of computer presentation in combination with the formal testing situation diverted processing resources needed for the analysis of higher order semantic meaning. The computer display represented a relatively unfamiliar means of displaying verbal information for these students. Indeed, informal questioning revealed that most of them had had no prior experience with microcomputers, with the exception of video games.

The practical implications of these data for the use of video text are clear: Readers who are used to reading texts printed on paper are initially less efficient in extracting meaning from computer-presented text. This problem is most apparent when an individual must adapt to the unfamiliar mode of presentation in the early stages of a new task. Even a simple operation such as pressing a key to change screens could be distracting to a new user. The present data suggest, however, that, after subjects have had sufficient practice on the task itself, comprehension can be equally accurate from textual material printed on paper or displayed on a video screen.

These data have rather urgent implications for the use of computercontrolled experiments in psychological research, especially research on reading. The large differences observed here in the computer-first condition suggest that subjects' reading processes in the early phases of computer-controlled tasks may differ markedly from traditional reading 
behavior. The problem may be especially acute when experimental subjects are required to read computer-presented text for a relatively brief period of time, as they are in the majority of laboratory studies. Unless subjects are given extensive practice with a specific task before testing begins, the data acquired in such studies may misrepresent the underlying processes in as yet unknown ways.

Although the present results indicate that comprehension from computer text is initially less efficient, they do not reveal the nature of the differences in processing that underlie this difficulty. More research is needed to assess the cognitive consequences of reading text from video displays, preferably research that examines the comparability of specific reading phenomena across different presentation modes. For the present, these data suggest caution in the use of computer-presented text in studies of reading processes that utilize brief experimental sessions.

\section{REFERENCES}

Baddeley, A. D. (1978). The trouble with levels: A reexamination of Craik and Lockhart's framework for memory research. Psychological Review, 85, 139-152.
BELMORE, S. M. (1983). RELEASE FROM PI: Comparison of traditional and computer modules in an experimental psychology laboratory. Behavior Research Methods \& Instrumentation, 15, 191-194. BEVAN, N. (1981). Is there an optimum speed for presenting text on a VDU? British Journal of Man-Machine Studies, 14, 59-76.

Craik, F. I. M., \& LockhaRT, R. S. (1972). Levels of processing: A framework for memory research. Journal of Verbal Learning and Verbal Behavior, 11, 671-676.

Didas, M. (1962). Vitalized English (5th ed.). New York: College Entrance Publications.

Mourant, R. R. (1981). Visual fatigue and cathode ray tube display terminals. Human Factors, 23, 529-540.

Muter, P., Latremouille, S. A., Treurniet, W. C., \& Beam, P. (1982). Extended reading of continuous text on television screens. Human Factors, 24, 501-508.

Nelson, M. J., \& Denny, E. C. (1960). The Nelson-Denny Reading Test. Boston: Houghton-Mifflin.

(Manuscript received for publication September 7, 1984.) 